while that of the upper surface was aerobic, becoming anaerobic only after burial by a thin layer of sediment. In the highly pyritic humulites, coprolites are not flattened and sulphides are confined to the fæcal mass. This results in smaller loss in volume, and suggests continuous aerobic decomposition.

Detailed investigations of vertical sections cut through fossil gastric residues, in which the escape effects of a gas bubble are clearly visible, are used to show that a mud cover, equivalent to 1-2 mm of shale, was deposited on fossil specimens from the time of their initial 'deposition' to the end of aerobic gas release in the carcasses. It is suggested that the cyclic character of the shale may be best interpreted by supposing that each pair of 'grey and black levols' represents an annual deposit, the low- and high-water alternations representing dry and wet seasons and thus suggesting sub-tropical climatic conditions.

Microstructural studies of the shales and their fossil content suggest that the muds wore nearly compacted at the time of deposition and, in contrast to other less carbonaceous marine muds, that they suffered little subsequent compaction under loading.

Analysis of the fossil content suggests the occurrence of three burial communities in the Mecca Quarry. The oldest is a well-preserved productid brachiopod, 'shelly' sessile, benthic community, apparently representing an autochthonous fauna that lived under clear, well-oxygenatod water, but which was killed off by the introduction of black mud. In other places a similar fauna is broken and disturbed and is clearly allochthonous, representing a transgressive marine phase overlying a coal.

The two overlying communities consist of a predominantly Dunbarella-conodont fauna with less common inarticulate brachiopods, cephalopods and typical fish, which is rngarded as an autochthonous, brackish or marine mobile epifaunal community, and the 'typical' Mecca fauna, which is dominated by vertebrates, containing up to 12 shark genera, as well as other groups. The only common invertebrate is a phyllocarid. This fauna is regarded, for reasons noted here, as an autochthonous thanatocoenose. Somewhat different burial communities are recognized in the Logan Quarry, but it is argued that the differences are the result of local samples of a single biotope, the overall aspects of the faunas being similar.

The annual burial rate of vortebrates at Mecca Quarry is estimated to be 475 individuals per $100 \mathrm{~m}^{2}$, a figure which is held to suggest a very high density of the living population. The vertical stratigraphic Mecca-Logan sequence is interpreted as a salt, brackish-fresh, salt cycle.

A final synthesis relates the detailed local physiographic régimes associated with the marine transgressions to their ecological effects. The pioneer community is dominated by fish in those cases where it is associated with incoming fresh water, and by Dunbarella where it is marine. Tho productid shell breccia is regarded, not as a pioneer community, but as a pre-transgression littoral and inlet community. The fossil distribution suggests that Dunbarella was stenohaline, incapable of salinity adjustments, whereas the other faunal elements, and the 'flotant' vegetation, were euryhaline. The Mecca site represented a deltaic coastal plain on the eastern shore of an epicontinental sea and the ecology of residual ponds and the freshwater environment (represented by the Garrard Quarry) is also reconstructed.

It may be argued that such a detailed and laborious study as this could have been more usefully applied over a wider area. For this is micropalæoecology, providing a limited number of carefully supported conclusions about a very restricted area, rather than grand but tenuous conclusions about Pennsylvanian environments across the face of the Earth. But in this very restriction lies its value, just as it was largely the fact that sixteenth- and seventrenth-century scholars became willing to forgo the joys of spoculation on ultimate causes and relationships for the disciplined, empirical study of local, restricted and carefully dofined problems, ovents and processes that led to the surge of scientific knowledge that marked that period of history.

The publication is well produced and illustrated with 56 plates and 51 text-figures. In an era of universal and inevitable editorial restriction of manuscript content it stands no less as an example of the value of unfettered monographic publication than it doos as a most notable contribution to palæoecology. F. H. T. RHodes

\title{
THE FANNING ISLAND EXPEDITION, 1963
}

$\mathrm{T}$ HE Fanning Island Expedition, consisting of four zoologists supported by the U.S. National Science Foundation and the Cocos Foundation, Inc., and sponsored by the University of Hawaii, carried out field studies and made collections of certain shoal water marine invertebrates on Fanning Island atoll, Line Islands, Pacific Oceania, during June 22-August 24. Fanning Island is situated in the equatorial current complex. These water masses could provide long-lived pelagic larvæ with the means of dispersal between the Indo-Pacific and the Atlantic-East Pacific faunal regions. The primary goal of the Expedition was to make collections of the sponges, corals, bivalved molluses and cirripeds for systematic treatment. It is hoped that this will provide fresh data for an analysis of the distribution of these groups in the eastern extremity of the Indo-Pacific region with special reference to the East Pacific Barrier.

Investigations by individual investigators on their special groups have provided information on several aspects of coral-reef biology which have hitherto received little attention. Studies on the Porifera included observations and experiments in the field on the effects of both grazing by fishes and of sedimentation on sponge survival. Data on stianding crop and gross productivity were recorded for two species.
Animals and algae associated with the stony corals were observed in an attempt to discover something of the natural history of the associations. Observations were made on the predation of corals by fishes and by invertebrates, the destructive action of surge on the outer reef, and sedimentation on the lagoon reefs. Sub-fossil corals were collected from large 'storm rocks' in which the coral colonies appeared to be oriented as they might have grown on the reef.

Studies of molluses included experiments in the field of the behavioural responses of the giant clam, Tridacna, to the presence of sediment and of fishes. The results were correlated with the anatomy of the nervous system. Observations were made of the anatomy of certain coralliophillid gastropods. A collection was made of sub-fossil shells from dry 'lakes'.

Collections were made of terrestrial, semi-terrestrial and marine crustaceans. Feeding mechanisms of certain cirripeds were observed under laboratory conditions. A hitherto unknown and complex feeding behaviour performed by a species associated with large decapod crustaceans was demonstrated and described.

Aside from special investigations and collections, the Expedition sought to record something of the biota and general physiographical features of the atoll so that it 
might be compared with the other atolls which huve been similarly examined. To this end an obsorvational transoct was mado across a large leeward islet from $500 \mathrm{~m}$ in the lagoon, across tho land to a point $300 \mathrm{~m}$ out from the seaward shoreline. Along the transcet the most obvious fontures were recorded, including depth or elevation, dominant biota, characteristics of the sub-stratum and the tidal flux of the freshwater lons. Tho foatures noted on the transect were compared with features at other sites around the atoll.

The structure of Fanning Tsland and the unusually calm weather during the Expedition's activities allowed observations and collections to be made on the outer reef from the breaking surf to a depth of approximately $30 \mathrm{~m}$, with the aid of self-contained underwater breath- ing apparatus. A dotailod examination was mado of tho looward sea reef; but only general features were observed on the windward sea reef outside the surf. The biota and physical foatures associated with tho controversial 'Ten Fathom Torrace' were given due consideration.

The investigators and their special groups woro: G. I. Bakus, Allan Hancock Foundation, University of Southern California, Los Angeles (Porifera); S. A. Wainwright, correspondent to the Expodition. Woods Hole Ocoanographie Institution, Woods Hole, Mass. (Soloractinia and hydrocorals); C. R. Stasek, Scripps Institution of Oceanography, La Jolla, California (Mollusca Bivalvia); W. A. Newman, Museum of Comparative Zoology, Harvard Univorsity, Cambridge, Mass. (Cirripedia).

\title{
INTERNAL SEDIMENTATION STRUCTURES OF WELL-WASHED SANDS AND SANDSTONES IN RELATION TO FLOW CONDITIONS
}

\author{
By J. R. L. ALLEN \\ Sedimentology Research Laboratory, Department of Geology, University of Reading
}

$\mathrm{T}$ HE three commonest internal sesdimentation struetures of well-washed sands and sandstones are: (1) cosets of small-scale cross-stratified sets, in which the thickness of an individual sot moasuros several millimetres or a few centimetres and the threc-dimonsional form of onch sot is usually tabular or scoop-like; (2) cosets of large-scale cross-stratified sets, in which the thickness of an individual set measures decimotres or motros and the form of tho set is tabular or scoop-like; (3) even and essentially horizontal laminations a millimetre or so in thickness with the surfaces of the laminæ marked by primary current lineation.

Sorby ${ }^{1,2}$, as long ago as the 1850 's, recognized theso three structures as charactoristic of three major sandstone facios. On the basis of experiments on sand transport, he attempted to use the structures to deduce the flow conditions under which particular rocks wero deposited. In this endeavour he was not completely successful, and it is now necessary in the light of subsequent work, by Simons and colleagues ${ }^{3,4}$ and reported in this article, to revise his scheme of sandstone facies in relation to flow conditions, to provide sedimentologists with a more accurate interpretative tool.

Small-scale cross-stratification. It is now fairly cloarly understood in throo-dimensional terms that small-scalo cross-stratification forms are genorated by the migration of small-scale asymmetrical ripples ${ }^{5,6}$. The threo-dimensional form of the sots is recognized to depend on the shape of the parent ripples and on the conditions of sediment supply. Simons et al..$^{3,4}$ have demonstrated that smallscalo ripples are formed at relatively low flow intensities in the lowor flow rogime, boginning from the intensitylovel necessary to start grains moving.

Small-scalo cross-stratification in sands and sandstonos may therofore be interproted as probably indicating a relatively low flow intensity in the lower flow regime.

Large-scale cross-strutification. Knowing that largo-scalo asymmetrical ripples are cross-stratified internally ${ }^{3,7}$, it is highly probable that cosets of large-seale cross-stratified sets were deposited from migrating trains of the large ripples, As in the oase of the small sets, the throedimensional forms assumnd by the large-scale sets appoar to depend on the shapes of the lange ripples and on the scdimont supply conditions. It was shown by Simons et al. ${ }^{3,4}$ that largo-scaln rippless formed in the lowor flow régime at a rolatively high flow intensity, above that nocessury to generate small-scalo ripples.
Lamination and lineation. Evenly laminatod sandstones with primary current lineation record repeated aggradn. tions, accompanied by forward grain translation, on sodiment-wator intorfaces that were essentially plane. Primary current lineation ${ }^{8}$ consists of parallel ridges and hollows of low relief on the parting surfaces of relatively fine-grained, evonly laminated, woll-washod sandstones (Fig. 1). Work on numorous examples from the Lower OId Red Sandstone (Lower Devonian) of the Welsh Bordorland has shown that the lineation is associated, in the plane of tho bedding, with a parallel preferred dimensional orientation of the quartz sand grains and, perpendicular to the bedding but parallel to the linoation, with a low-angle grain imbrication. The association of lamination and lineation in shallow water sandstones has been reported by many geologists in recent years, but apparently was first described by Sorby ${ }^{1,2}$, who also attempted tho first oxperimental explanation of this combination of structures. Sorby obsorved that "graining in the line of the current", as he described primary current lineation, could be formed on a sand bod through the activity of moving water at flow intensities both lowor and higher than were necessary to generate small-scale ripplos. Sorby ${ }^{2}$ concluded finally, however, that the lineation was normally formod at flow intensities intermediato botween those required to initiate grain movement and to form small ripples.

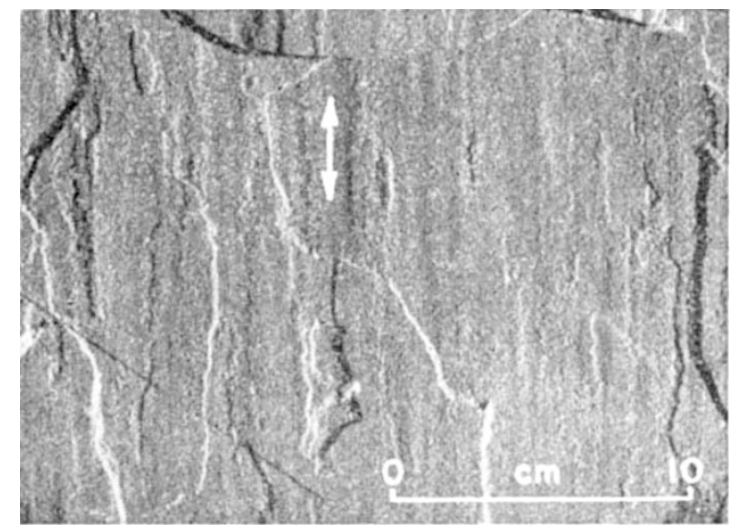

Fig. 1. Sandstone bedaing planes showing primary current lineation from the Brownstones (Lower old lied Sandstone), liorest of lyean. 